\title{
Holmium laser ablation: a successful treatment option for an obstructing ureteric valve
}

\author{
Muhammad Z. Aslam, MD, MRCS; B.D.R Gowda, MD, FRCS
}

\begin{abstract}
We present a case of an 80-year-old woman with intermittent flank pain, who was found to have a ureteric valve causing significant hydronephroureterosis. We discuss the role of holmium laser in successfully ablating the lesion, and present a review of the literature.
\end{abstract}

Can Urol Assoc J 2010;4(1):E15-E16

\section{Introduction}

Ureteric obstruction is a very common condition, resulting from various causes, most notably calculi, tumours, blood clots, ureteric strictures and retroperitoneal fibrosis. Congenital ureteral valves are a very rare cause of ureteric obstruction. Most cases are associated with other congenital urological malformations and are diagnosed during operation or autopsy. ${ }^{1}$ We report the case of an 80 -year-old woman with a ureteric valve who presented with hydronephroureterosis, which was treated with holmium laser ablation.

\section{Case report}

An 80-year-old woman presented with a history of rectal bleeding. A computed tomography (CT) scan of the abdomen demonstrated a left hydronephroureterosis with the possibility of thickening or an intraluminal lesion in distal left ureter. During the urological consultation, the patient gave a history of moderate intensity intermittent flank pain. Renal functions were within normal limits.

Retrograde studies, performed for further evaluation, demonstrated a dilated ureter about $5 \mathrm{~cm}$ proximal to the vesicoureteric junction and a dilated pelvicalyceal system which appeared to be longstanding (Fig. 1). A ureteroscopy was performed, which demonstrated a membranous diaphragmlike valve at the site of calibre change of ureter (Fig. 2). The segment of the ureter distal to the valve was of normal calibre. Complete ablation of the valve was performed using holmium laser, at a power setting of $1.0 \mathrm{~J} \times 10 \mathrm{~Hz}$ (Fig. 3).
Our patient made an uneventful postoperative recovery and continues to remain completely asymptomatic, with normal renal functions, 6 months after the operation.

\section{Discussion}

Diaphragmatic ureteral valves are a very rare cause of ureteric obstruction. They have been observed to occur in utero due to improper recanalization or insufficient vascular supply. ${ }^{2}$ Kilciler and colleagues, however, described ureteral valves to be iatrogenic in origin which resulted from a ureterolithotomy being performed on their patient 6 months before the diagnosis. ${ }^{3}$ Govaerts and colleagues reported a unique case of ureteral valve which was found in an ectopic ureter discharging into seminal vesicle and was associated with renal dysplasia. ${ }^{1}$

These valves are either seen as a single annular lesion with pinpoint openings ${ }^{4}$ or as eccentric mucosal cusps, ${ }^{5}$ with an equal incidence on both sides. ${ }^{6}$ Microscopically, true ureteral valves contain all layers of the ureter (epithelium, lamina propria and smooth muscle) except the adventitia. ${ }^{1}$

The most common presentation of this condition includes flank pain, gross hematuria and urinary infection. 1,3,7 In one reported case, a non-functioning kidney was found on initial investigation which required a nephrectomy. ${ }^{6}$

Various reports suggest that initial investigations, such as excretory urography and a CT scan, were able to demonstrate ureteric obstruction with hydronephrosis, but the cause of obstruction could not be established; a definitive diagnosis could only be made by retrograde pyelography and ureteroscopy. ${ }^{1,3,7}$ Ureteric strictures, whether acquired or congenital, remain another common cause of ureteric obstruction and should be ruled out. A ureteric stricture is defined as a constantly narrowed segment of a ureter. Wall and Wachter proposed a criteria for diagnosis of ureteric valves which consisted of anatomically demonstrable transverse folds of ureteral mucosa containing bundles of smooth muscle fibres, obstructive disease changes proximal to the valve with a normal ureter distally, and no other evidence of mechanical or functional obstruction. ${ }^{4}$ In our case, the diagnosis of a ureteric valve was made based on direct 
visualization at ureteroscopy and our findings were consistent with the above description of a ureteric valve. In addition, ureter distal to this valve was of normal calibre and completely ruled out the possibility of a stricture.

Our patient was successfully treated by holmium laser ablation, a relatively new treatment modality; the first case was reported in 2006. ${ }^{7}$ Other minimally invasive treatment options described include the removal of the valve with biopsy pens without resec-

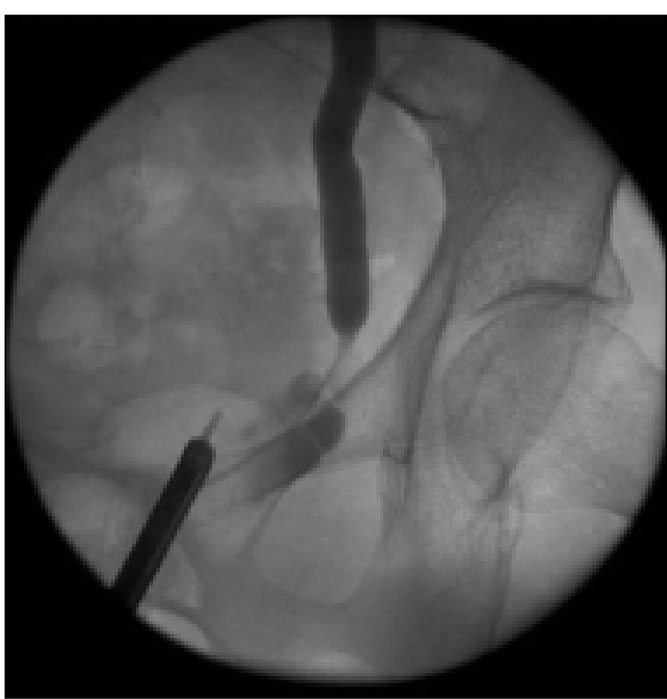

Fig. 1. Retrograde studies demonstrating dilated ureter proximal to the site of the ureteric valve.

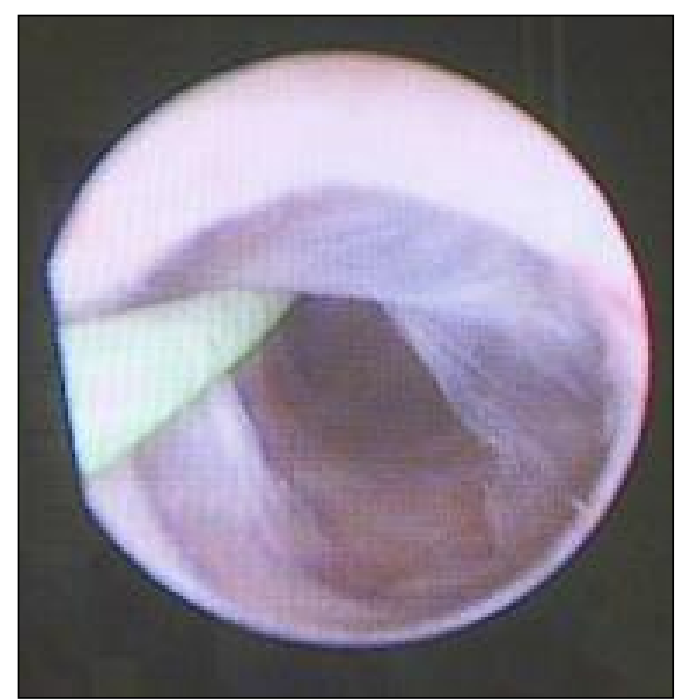

Fig. 2. Membranous diaphragm-like valve demonstrated on ureteroscopy. tion $^{3}$ and the endoscopic incision with a hook-shaped cold knife on the dorsal side of the ureter. ${ }^{8}$ Ureteric valve causing significant obstruction could also be surgically excised with primary ureteroureteral anastomosis or ureteropyelostomy. ${ }^{9}$ Where renal function has been significantly compromised, a nephrectomy should be considered. ${ }^{1,6}$

\section{Conclusion}

Ureteral valves are an uncommon cause of ureteric obstruction which can be either congenital or iatrogenic in origin. Though radiological imaging demonstrates obstruction, retrograde pyelography with ureteroscopy remain the gold standard for diagnosis. Clinicians can be reassured that successful ablation can be achieved using holmium laser.

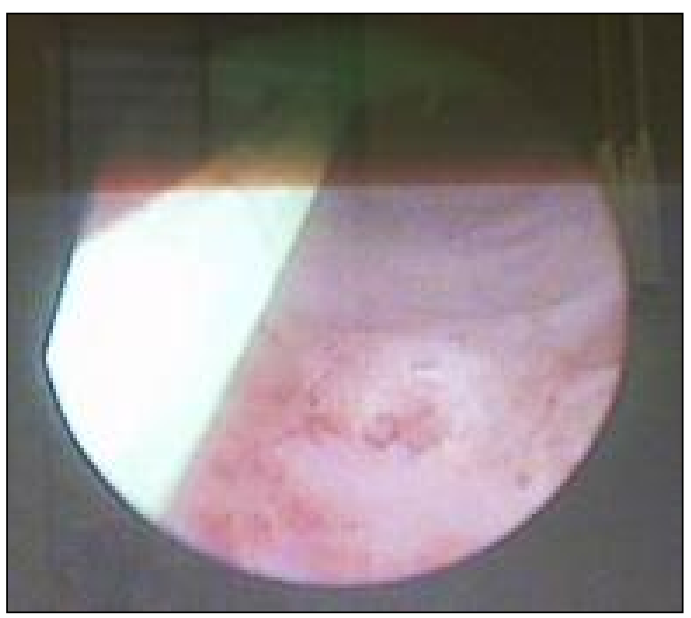

From the Urology Department, Hambleton Wing, Friarage Hospital, South Tees Hospitals NHS Foundation Trust, Friarage Hospital, Northallerton, United Kingdom

Competing interests: None declared.

This paper has been peer-reviewed.

\section{References}

1. Govaerts J, Huysmans G, Wouters Y. Ureteric valves in an ectopic ureter associated with renal dysplasia. Br J Urol 1991;67:554-5

2. Docimo SG, Lebowitz RL, Retik AB, et al. Congenital midureteric obstruction. Urol Radiol 1989;11:156-60.

3. Kilciler $M$, Erdemir $F$, Bedir $S$, et al. Ureteral membranous band causing vereteral obstruction after the ureterolithotomy. Int Urol Nephrol 2006;38:467-8.

4. Wall B, Wachter E. Congenital ureteral valve: its role as a primary obstructive lesion. Classification of the literature and report of an authentic case. J Urol 1952;68:684-90.

5. Cussen $\mathrm{L}$. The morphology of congenital dilation of the ureter: intrinsic lesions. Aust N Z J Surg 1971;:41:185-7.

6. Sant GR, Barbalias GA, Klauber GT. Congenital ureteral valves- an abnormality of ureteral embryogenesis? J Urol 1985;133:427-31.

7. Singh S K, Wadhwa P. Ablation of diaphragmatic annular ureteral valve with holmium laser. Int Urol Nephrol 2006;38:157-9.

8. Nishio S, Hamada H, Yokoyama M. Endoscopic incision for the treatment of a ureteric valve. $\mathrm{Br} J \mathrm{UrOl}$ 1999;83:1081-2.

9. Manzoni C. Urethral valves. Rays 2002;27:87-8.

Correspondence: Dr. Muhammad Z. Aslam, Urology Department, Hambleton Wing, Friarage Hospital, Northallerton, United Kingdom DL6 1JG; mzaslam77@yahoo.com

Fig. 3. Ablation of the valve achieved successfully with holmium laser. 